\title{
What to do about the Canadian Resident Matching Service
}

\author{
C. Ruth Wilson MD, Zachary N. Bordman MD
}

Cite as: CMAJ 2017 November 27;189:E1436-7. doi: 10.1503/cmaj.170791

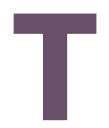

he system for matching Canadian medical graduates to residency positions is broken. Last year, 68 medical graduates went unmatched - a record high. Yet, there were 64 residency positions that went unfilled, included 56 in family medicine in Quebec. ${ }^{1}$ Even graduates who do find positions spend far too much time applying to multiple programs, chasing interviews and travelling all over the country, desperately trying to impress residency program directors. It is time for reform. Medical schools, medical students, residency programs, the Canadian Resident Matching Service (CaRMS) and provincial governments need to work together to change a system that, although it works for many, leaves many others unmatched, feeling hopeless or worse; ${ }^{2}$ leaves residency positions in disciplines of need unfilled; and ultimately fails to meet the needs of Canada's health care system.

Provincial governments determine the number and mix of residency positions funded. This is partly based on history and projections of societal need, but other factors also play a role. For example, unmatched positions in Quebec were in areas where fluency in French is required. The climate for family physicians in the province is also considered by some to be too restrictive. ${ }^{3}$ In Ontario, none of the family medicine programs, except for the University of Toronto's, filled all their residency positions on the first iteration of the match. Years of dispute between the Ontario Medical Association and the Ministry of Health and Long-term Care over physician remuneration may be taking its toll. ${ }^{4} \mathrm{About}$ a quarter of respondents to a recent survey of medical graduates at the University of Toronto reported a decreased desire to enter family medicine because of recent changes to health policy (Dr. Z. Bordman, University of Toronto: unpublished data, 2017). Clearly, planning Canada's health human resources is complicated, and getting the right number of physicians into various specialties to meet population needs is no exception.

It does not help that medical students are put under pressure to choose a specialty early in their medical training. Some specialties are more competitive than others, and medical students interested in a particular career try to obtain electives and references that increase their chances in the resident matching service. Some realize too late that they have chosen the "wrong" electives and are afraid to replace them with other experiences for fear of being

\section{KEY POINTS}

- The system for matching Canadian medical graduates to residency positions is broken, with record high numbers of unmatched graduates.

- Medical students are put under pressure to choose a specialty early in their medical training and are counselled to apply to many programs to increase their chances of matching, which consequently burdens the residency programs with excessive numbers of applicants.

- Medical schools must continue an emphasis on generalist skills and preparation for careers in specialties and geographic areas of societal need, as well as provide ongoing support for medical students through and after the match from the Canadian Resident Matching Service, particularly for unmatched students.

- Planning for the health human resource needs of Canada is complicated, but provincial governments should increase the ratio of slots to graduates from 102/100 to something closer to historical averages of $110 / 100$, which would allow more flexibility for transfer between programs and decrease the possibilities of unmatched graduates.

labelled as unprofessional. Moreover, they may feel compelled, and are often counselled, to apply to many programs to increase their chances of matching; graduates apply to 18 to 19 programs on average. ${ }^{5}$ The resulting deluge of applications means training programs must look for reasons to eliminate candidates, such as a lack of suitable electives or poor references.

Canadian medical graduates face additional pressure because of competition from international medical graduates. Practices vary across Canada as to how many international medical graduates can access the resident matching service, whether in the first or second iterations, or in a parallel but separate match. Still, the additional competition decreases the chances of a match for Canadian graduates who do not match on the first iteration. In the first iteration of 2017, 93.5\% of Canadian graduates matched, leaving 189 unmatched. In the second round, there were 219 positions available for 216 Canadian graduates (including ones from previous years of graduation) and 989 international medical graduates. Fifty-three of the available positions were filled by international medical graduates ${ }^{6}$ 
A decades-long policy assumption that all graduates of Canadian medical schools will have a Canadian residency position available to them suggests that every graduate of a medical school in Canada should have an opportunity to match to a residency program in this country. Indeed, because the cost of medical education is still borne largely by public funding, it seems reasonable that wise public investment would ensure that graduates from medical schools in Canada are prepared by residency programs to practice in Canada. Therefore, provinces should increase the ratio of slots to graduates from 102/100 to something closer to historical averages of $110 / 100$, which would allow more flexibility for transfer between programs and decrease the possibilities of unmatched graduates. Unfilled slots could then be offered to international medical graduates if there is a population need, or could be left unfilled if no need is identified.

In Europe, positions in medical schools are less competitive on entry, but a winnowing process ensues, so that not all graduates are guaranteed a career in medicine. If Canada were to change its policy and adopt the European model, our medical schools would need to change their focus and curriculum to include career counseling that prepares students for potential nonclinical careers in fields such as medical information technology, business or the pharmaceutical industry. ${ }^{7}$.

Medical schools and students need to continue to emphasize generalist skills as a preparation for careers in specialties and geographic areas of societal need. We must encourage a culture of openness so that medical students can speak freely regarding their ambivalence about career choices and are_encouraged to explore their options. Providing ongoing support and mentoring through medical school and after the match through the resident matching service is crucial, particularly for unmatched students. Some medical schools are providing additional funding for postgraduate clinical experience, along with counselling and support, for unmatched graduates. Consideration could be given to setting a cap on the number of programs to which each student may apply, to decrease the burden and cost of the process on both students and programs.

What is imperative is that no medical graduate should feel that the obstacles standing in the way of a fulfilling career are insurmountable.

\section{References}

1. Match results for the second iteration of the 2017 R-1 Main Residency Match. Ottawa: Canadian Resident Matching Services; 2017. Available: https://www. carms.ca/en/residency/r-1/match-results/ (accessed 2017 July 6).

2. Woods A. Tragic case of Robert Chu shows plight of Canadian medical schoo grads. Toronto Star [Toronto]. Available: https://www.thestar.com/news/canada /2017/06/17/tragic-case-of-robert-chu-shows-plight-of-canadian-medical-school -grads.html (accessed 2017 July 6).

3. Vogel L. Record number of unmatched medical graduates. CMAJ News 2017 May 10. Available: http://cmajnews.com/2017/05/10/record-number-of-unmatched -medical-graduates-cmaj-109-5432/ (accessed 2017 Oct. 11).

4. Grant K. Ontario slashes fees it pays to doctors following negotiations. Globe and Mail [Toronto]. Available: https://beta.theglobeandmail.com/news/politics/ labour-talks-founder-between-ontario-and-doctors/article22461657/?ref=http:// www.theglobeandmail.com\& (accessed 2017 Oct. 11).

5. Moineau G. The unmatched Canadian medical graduate: the victim of a broken system [blog]. Ottawa: Association of Faculties of Medicine of Canada; 2017. Available: https://afmc.ca/blog/2017-06-08 (accessed 2017 July 6).

6. 2017 R-1 main residency match report. Canadian Resident Matching Service; 2017. Available: www.carms.ca/en/data-and-reports/r-1/r-1-match-reports-2017/ (accessed 11 Oct. 2017).

7. Sanfillipo A. Is every Canadian medical school graduate entitled to become a practicing physician [blog]? Kingston (ON): Queen's University; 2017. Available: https://meds.queensu.ca/blog/undergraduate/?p=3568 (accessed 2017 July 6).

\section{Competing interests: None declared.}

This article was solicited and has peer reviewed.

Affiliations: Department of Family Medicine (Wilson), Queen's University, Kingston, Ont.; Department of Family and Community Medicine (Bordman), University of Toronto, Toronto, Ont.
Contributors: Both authors contributed to the conception and drafting of the work, revised it critically for important intellectual content, gave final approval of the version to be published and agreed to be accountable for all aspects of the work in ensuring that questions related to the accuracy or integrity of any part of the work are appropriately investigated and resolved.

Correspondence to: C. Ruth Wilson, ruth.wilson@dfm.queensu.ca 